\title{
DISCOURSE ANALYSIS THEORY AND ITS ROLE IN DEFINING POLITICAL INTENT THE SPEECH OF HIS MAJESTY SULTAN QABOOS BIN SAID, MAY GOD REST HIS SOUL, AT THE OPENING OF THE SIXTH SESSION OF THE COUNCIL OF OMAN AS A MODEL
}

\section{Zahir Bin Marhoon Bin Khaseef AL-DAOUDI ${ }^{1}$}

\section{Istanbul / Türkiye \\ p. 256-267}

Received: $27 / 11 / 2021$

Accepted: $14 / 12 / 2021$

Published: 01/01/2022

This article has been scanned I iThenticat No plagiarism detected

\begin{abstract}
:
This research seeks to analyze the speech of His Majesty Sultan Qaboos bin Said, may his soul rest in peace, based on the theory of discourse analysis; This is because the text is the internal structure of discourse that consists of vocabulary, structures, and sentences, which helps to know the various rhetorical methods that His Majesty, may God have mercy on him, relied on to convince the recipient, and to clarify the linguistic effects that indicate the political and social functions that the discourse on democracy accomplishes for the actors; Because language reveals the depths of politics and its purposes, it is the first language of communication with citizens and the masses, and it has strength and ability to realize the common and speed of understanding, and the ability to influence the recipients and convince them.

Discourse analysis in this study, like the rest of the studies, depends on the vocabulary, structures, and sentences that make up the text. major.
\end{abstract}

Key words: Discourse Analysis, His Majesty Sultan Qaboos, May God Rest His Soul, Council Of Oman, Producer Of The Text, Recipient, Intentionality.

http://dx.doi.org/10.47832/2717-8293.15.19

1 (iD) Dr. , Sultan Qaboos University, Sultanate of Oman, zaher@ squ.edu.om, https://orcid.org/0000-0002-4597-4963 
نظرية تحليل الخطاب ودورها في بيان المقاصد السياسية خطاب حضرة صاحب الجلالة السلطان قابوس بن سعيد طيب الله ثراه في افتتاح الدورة السادسة لجلس عُمان أنموذجا

\section{زاهر بن مرهون بن خصيف الداودي2}

\section{الملخص:}

يسعى هذا البحث إلى تحليل خطاب صاحب الجلالة السلطان قابوس بن سعيد طيب الله ثراه، معتمدا على

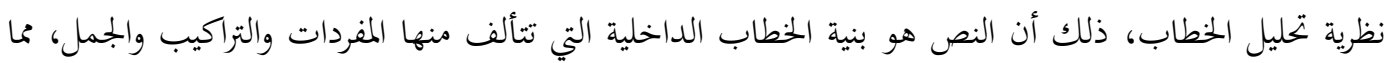
يعين على معرفة الأساليب الخطابية المتنوعة التي اعتمد عليها صاحب الجلالة طيب الله ثراه في إقناع المتلقي، وبيان الآثار اللغوية الدالة على الوظائف السياسية والاجتماعية التي ينجزها الخطاب عن الديمقراطية للفاعلين، ذلك أن

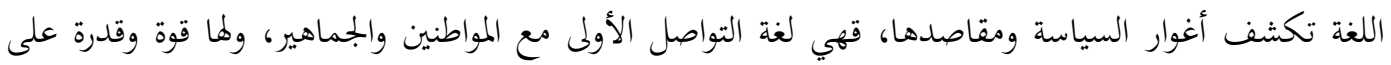
إدارك المشترك وسرعة الفهم، والقدرة على التأثير على المتلقين وإقناعهم.

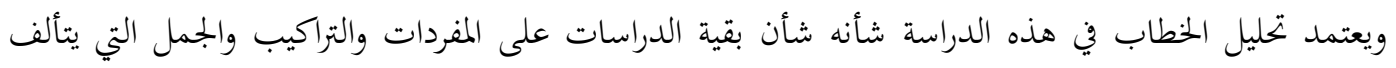
منها النص، كما يعتمد على السياق اللغوي والسياق غير اللغوي الذي يعنى بدراسة الخطاب في ضوء ظروف إنتاجه، ويشمل خصائصه الإدراكية والاجتماعية والثقافية، وارتباطه بالزمان والمكان، مما يشكل بنية نصية كبرى. الكلمات المفتاحية: تحليل الخطاب، جلالة السلطان قابوس طيب الله ثراه، بجلس عمان، منتج النص، المتلقي، القصدية.

النص هو بنية الخطاب الداخلية التي تتألف منها المفردات والتراكيب والجمل، بغية معرفة الأساليب الخطابية المتنوعة التي

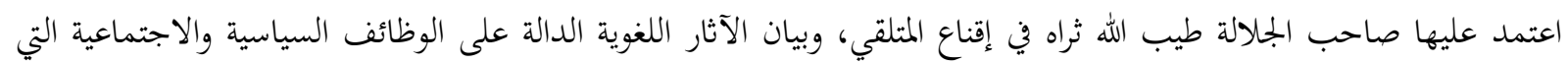
ينجزها الخطاب عن الديمقراطية للفاعلين، ذلك أن اللغة تكشف أغوار السياسة ومقاصدها، قهي لغة التواصل الأولى مع المواطنين والجماهير، ولها قوة وقدرة على إدارك المشترك وسرعة الفهم، والقدرة على التأثير على المتلقين وإقناعهم. ويعتمد تحليل الخطاب في هذه الدراسة شأنه شأن بقية الدراسات على المفردات والتراكيب والجمل التي يتألف منها النص، كما يعتمد على السياق اللغوي والسياق غير اللغوي الذي يعنى بدراسة الخطاب في ضوء ظروف إنتاجه، ويشمل خصائصه

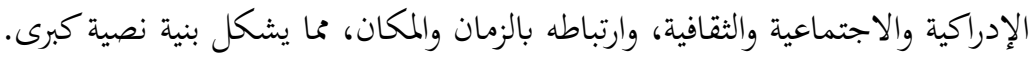

ونظرا لعزوف كثير من الباحثين عن دراسة الخطابات السياسية في عمان، وخطابات صاحب الجلالة خاصة، دفعني إلى اختيار هذا الموضوع خاصة أن هذا الخطاب (خطاب صاحب الجلالة في افتتاح مجلس عمان) أن استطاع منتجه في أن يحمل كلماته وبمله القصيرة معان سامية عظيمة، لن يتمكن من الوصول إلى كنهها إلا بدراستها والوقوف عند سياقاتحا المختلفة. ولا أزعم أن هذه الدراسة هي الدراسة الأولى لخطب صاحب الجلالة، إنما هناك دراسات سبقت هذهة هذه الدراسة، مع قلتها، أهمها:

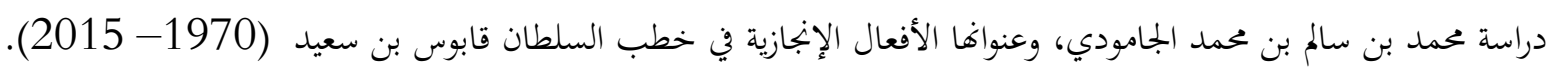


وقد كان هدف هذه الدراسة تحليل الأفعال الإنجازية في خطب السلطان الراحل السلطان قابوس بن سعيد طيب الله ثراه،

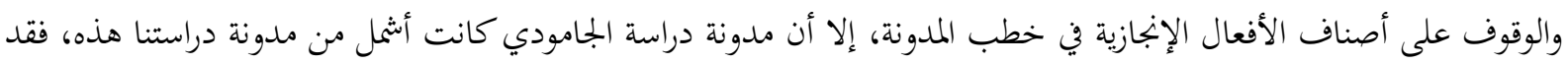
اعتنت دراستنا على خطابه طيب الله ثراه في افتتاح الدورة السادسة لمجلس عمان. كما أن هدف دراستنا ليس تتبع الأفعال الإنجازية، وإنما هدفنا الوقوف على المستويات اللغوية، والعلاقات اللغوية، التي وظفها السلطان الراحل حضرة صاحب الجلالة السلطان قابوس بن سعيد طيب الله ثراه في خطاباته السياسية، وقد اعتمد البحث البحث

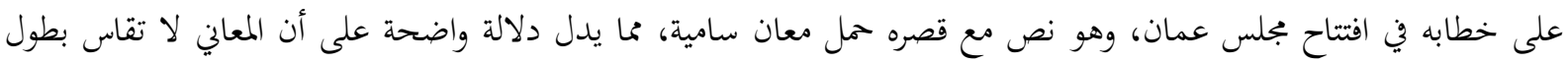
النصوص أو قصرها، وإنما تقاس بمضموها، ولن يتحقق هذا المضمون إلا بامتلاك الأدوات الصحيحة السليمة، وتوظيف القرائن المختلفة توظيفا يخدم معاني الخطاب ومضامينه السامية. وستعتمد الدراسة نظرية الاتصال في علم اللغة النصي، ذلك أن الاتصال نشاط اجتماعي حيوي، يتناقل الأفراد أو

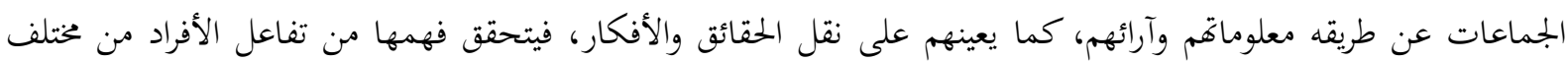
الثقافات والاتحاهات الفكرية للوصل إلى المعنى المنشود من هذه الرسائل.

وستقسم الدراسة إلى قسمين رئيسين هما القسم النظري وفيه سيبين البحث تعريف الخطاب السياسي نظريا، ثم القسم

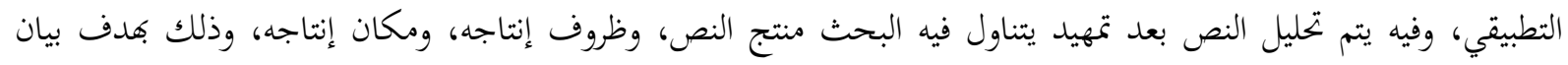

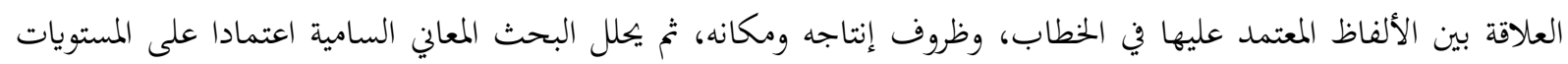

المختلفة.

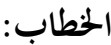

يعد أفلاطون أول من نظر إلى الخطاب، فقد ضبط المفهوم الفلسفي للخطاب استنادا إلى قواعد عقلية محددة، وهو أول من كشف المعنى الفلسفي للخطاب اليوناني.وبما أن الخطب تعبر عن حقائق واقعية بألفاظ واضحة مباشرة بعيدة عن الصنعة

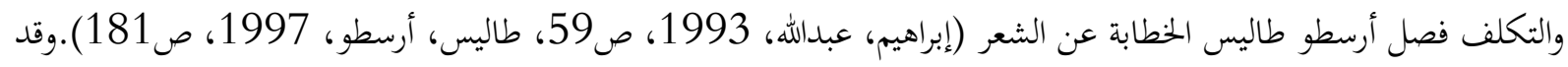

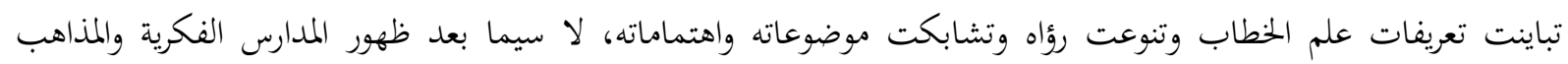

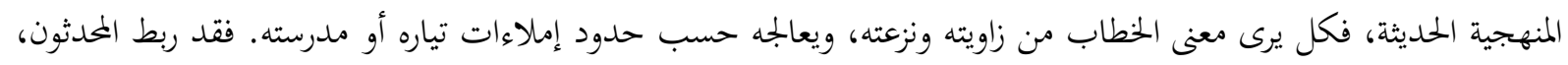

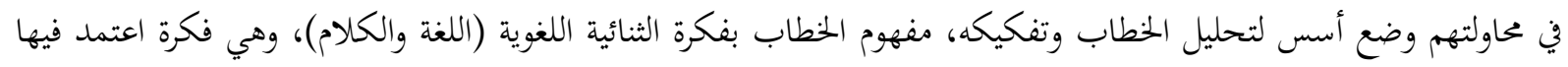

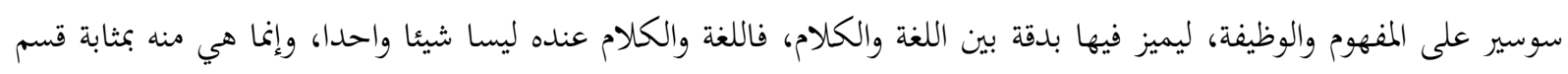

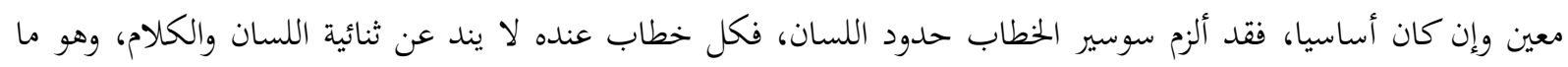

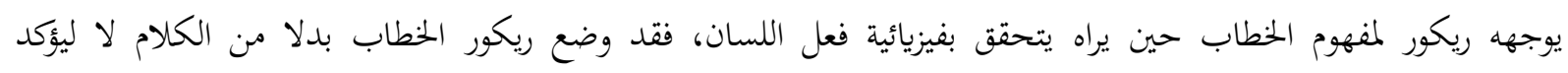

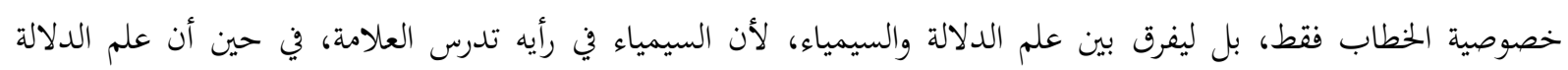

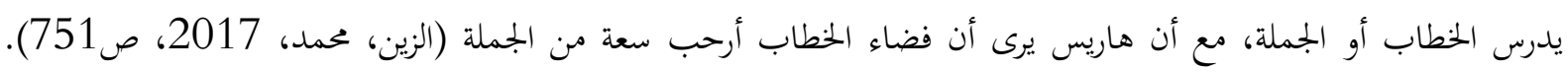

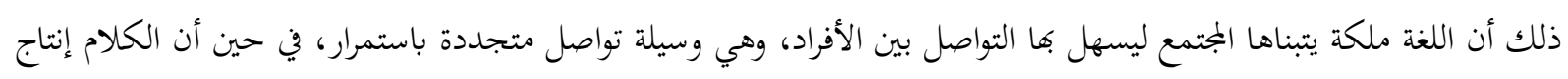

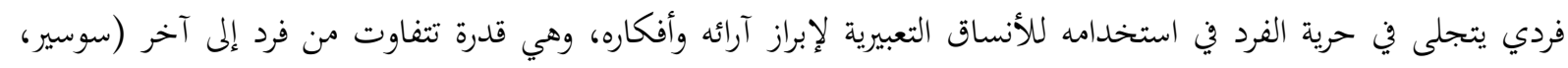

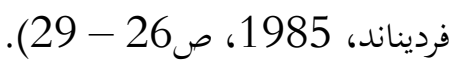

وقد اهتم إميل بنفينست بالتلفظ حين رأى أن الخطاب كل لفظ يفترض متكلما يهدف إلى التأثير في المستمع، فجعل

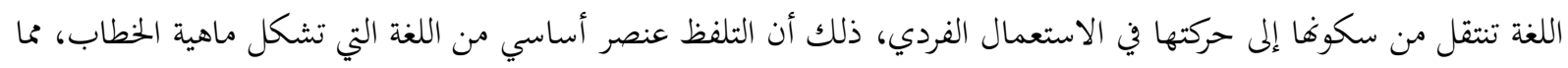


يتيح لنا بناء علاقة تفاعلية بين المخاطب والمتلقين، اللغة وسيلة للتعبير وأداة للتفكير وحقل للتأويل والتفسير، ولا يمكن بأي حال

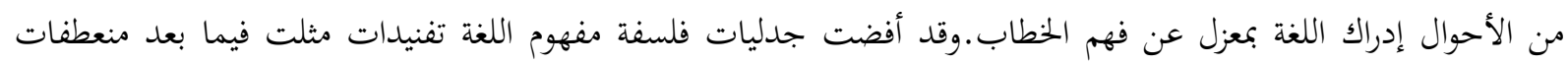
متداخلة، منها مفهوم الكلام، ومفهوم الجمملة، وصولا إلى مفهوم النص الذي استندت على إثره نظريات عنيت بتفسيره، وتفتيت

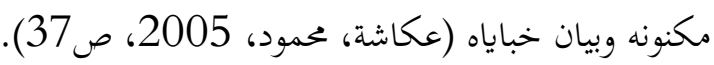
والخطاب كما يراه ميشيل فوكو مصطلح لساني وشكل أدبي يتميز عن غيره من الأشكال الأدبية بطريقة نظمه، وكونه نابتا

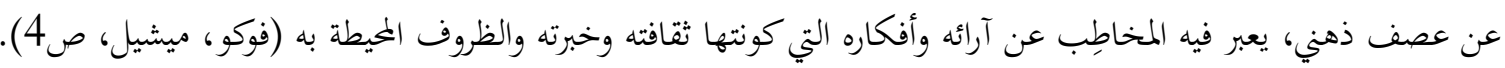
والخطاب السياسي هو خطاب السلطة يوجه عن قصد نحو المتلقي للتأثير فيه، وإقناعه بمضمون خطاب يتضمن أفكارا

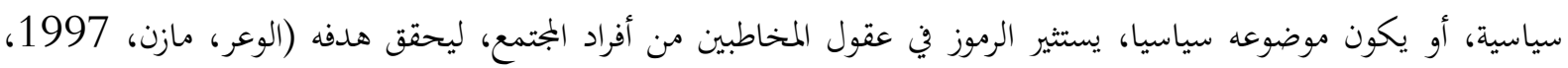

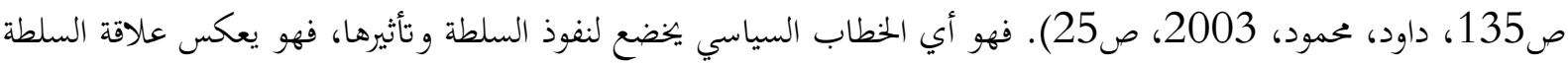

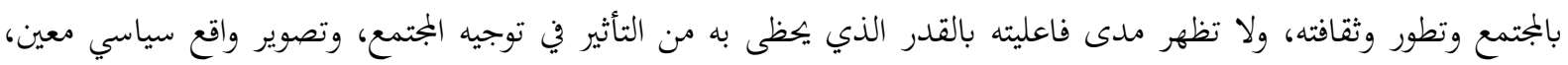
ومفاهيم سياسية يفهمها المتلقين في محيط اجتماعي معين، وهو يشكل وحدة لغوية خاضعة للتأمل، لدمج المتلقي بالأفكار والآراء

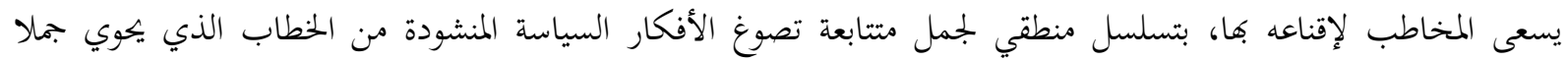
مصوغة بأسلوب يثير مشاعر المتلقي ويحرك فهمه، ليدرك مضمون الرسالة التي يتضمنها الخطاب، ويدرك القصد الذي أراده

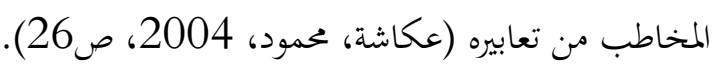
والخطاب السياسي شأنه شأن بقية الخطابات فإنه يعتمد اللغة أداة من أدواته، فيحقق السياسي براعة في انتقاء ألفاظه وتعابيره وصياغتها صياغة صحيحة سليمة ليؤثر في الرأي العام، وقد ربط ديل هايمز الكفاية الاتصالية بقدرة المتكلم على إنتاج منطوقات مناسبة لأنماط المواقف الاتصالية المختلفة، وعدم الاقتصار على تحقيق التواصل في نمط الجمل النحوية فقط، وإنما يتم

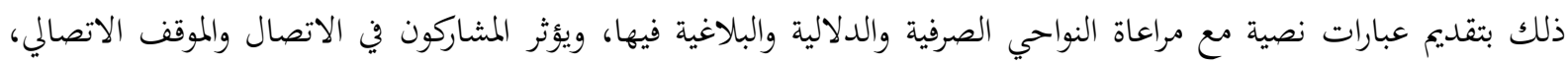

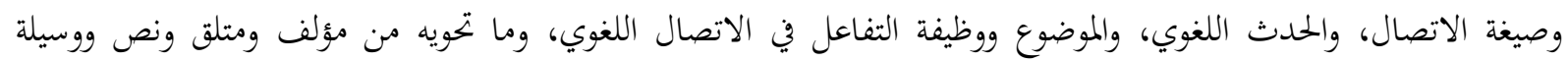

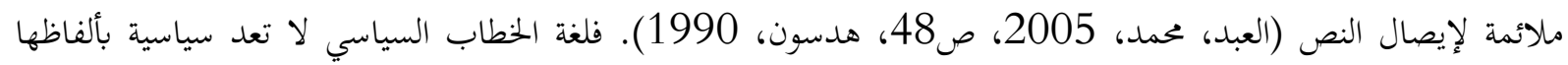
وعباراتا، وإنما بمعلوماتها المهمة التي تنقلها، ذلك أن الخطاب السياسي محفز للمثيرات الاجتماعية والسياسية التي تنعكس عليه،

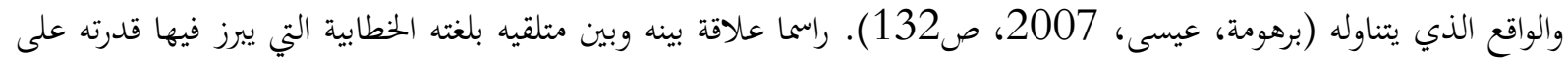

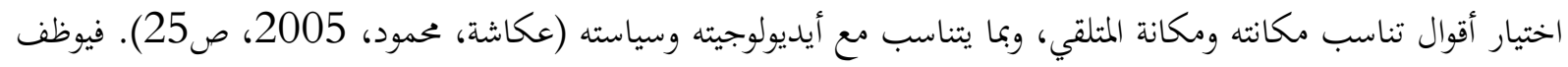

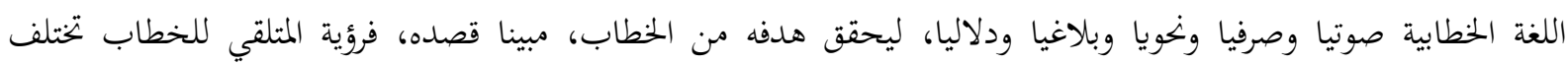
ومستوى فهمه وتحليله بناء على ما يمتلكه من خبرة وثقافة، ومع ما يتناسب هذه الخطابات ومعيات مع طبيعة المتلقي بتنوعها (الجابري،

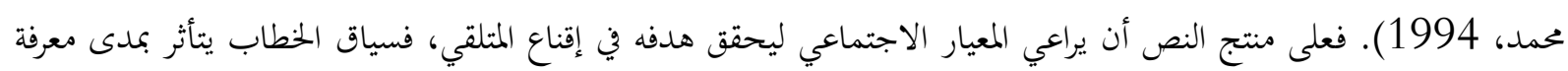

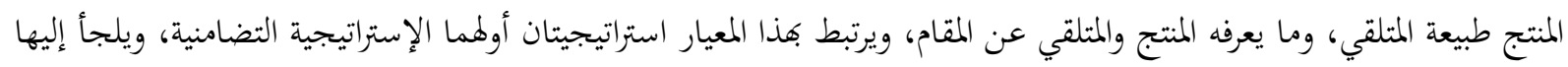

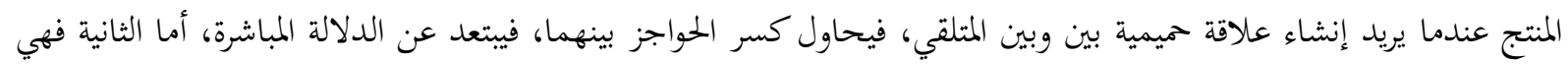

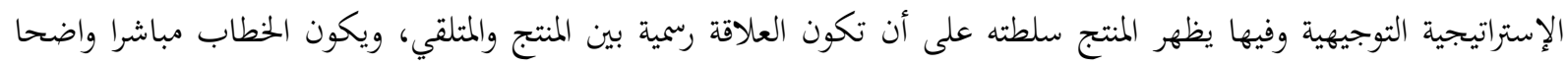

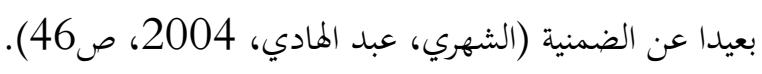


اعتمدت الدراسة على النص المسموع وهو خطاب صاحب الجلالة السلطان قابوس بن سعيد طيب الله ثراه، وهو نص

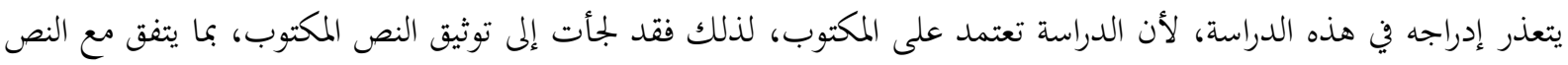

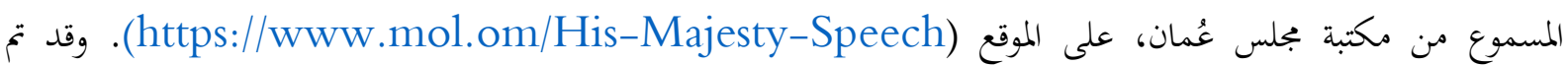

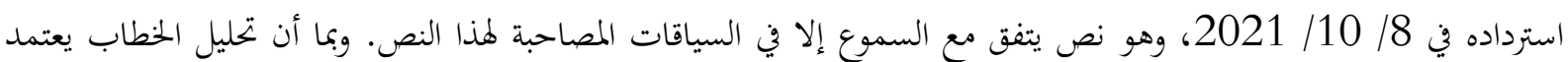
على المعطيات اللغوية، وغير اللغوية، ومنها السياق المصاحب للخطاب، فقد عاد الباحث إلى النص المسموع. ويمكن العودة إليه

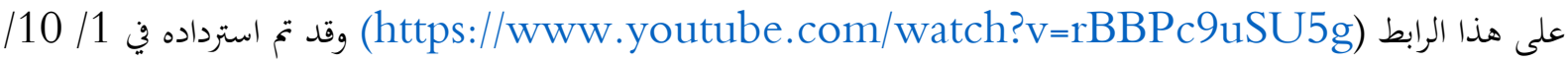
2021م، وهو تسجيل كامل لخطاب صاحب الجلالة السلطان قابوس في افتتاح الفترة السادسة لمجلس عمان الأحد 3 صفر 1437هـ، 15 نوفمبر 2015م، ونسج، خطاب ألقاه في حصن الشموخ، في ولاية منح.

\section{والنص المكتوب للخطاب، هو:}

$$
\text { بسم الله الرحمن الرحيم }
$$

الحمدُ له على ما أفاء به علينا من نِعم، وأسبغه من آلاء، والصلاةُ والسلامُ على من أُرسل رحمة للعالمين.

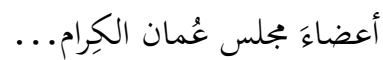
إنه ليسُرنا أن نلتقي بكم في هذا اليوم المهارك، لنفتتح أعمال الفترة السادسة لمجلس عُمان، متمنين أن تُكلل أعماله

$$
\text { بالتوفيقِ والسدادِ لحدمة هذا الوطن العزيز. }
$$

إن ما تحقق على أرض عُمان من مُنجزات في مختلف المجالات، لهي مبعث فخرِ ومصدر اعتزاز، وإننا نتطلعُ إلى مواصلة

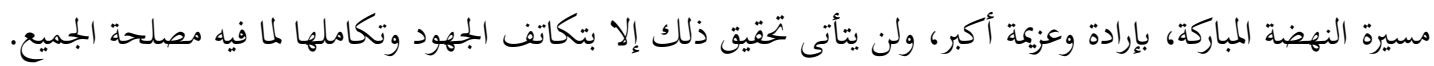

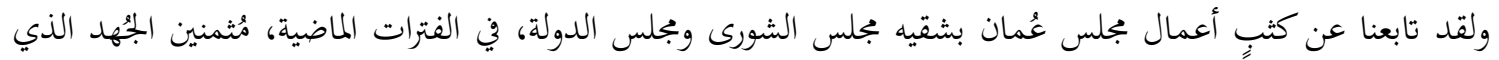
بذله المجلس خلالها، مما كان له الأثر الملموس للإسهام في دفع مسيرة التنمية الشاملة قُدماً نحو مزيلٍ من التطور والنماء.

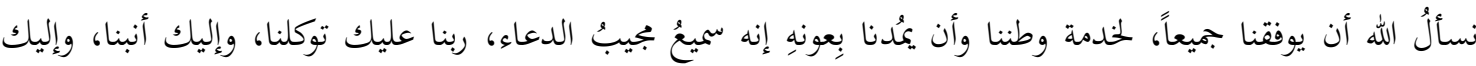
المصير، وُكل عام وبلادنا العزيزةُ وأبناؤها الأوفياء في خير ومسرة، وطنال والسلام عليكم ورمة الله وبركاته.

\section{تحليل خطاب حضرة صاحب الجلالة السلطان قابوس بن سعيد طيب الله ثراه في افتتاح بجلس عُمان:

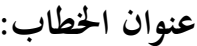

اهتم علم السيمياء اهتماما واسعا بالعنوان في النصوص الأدبية كونه "نظاما سيميائيا ذا أبعاد دلالية وأخرى رمزية تغري الباحث بتتبع دلالاته ومحاولة فك شفرته الرامزة"، فقد أصبح العنوان موازيا للنص لا يمكن بتحاوزه، فقراءة العنوان إنتاج الدلالة لتؤدي إلى التشخيص المطلوب أو المرسوم في ذهن المتلقي بل في تأويله ويف نموه باكتشاف الدلالات المخبوءة في نسيج العنوان،

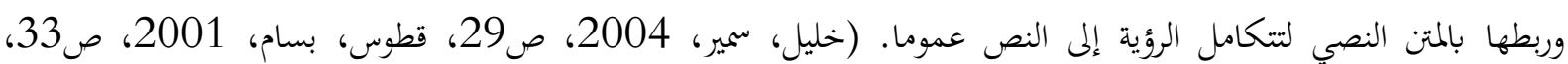

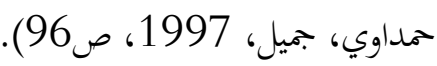
والعنوان هو العلامة الجوهرية والعنصر الأهم من عناصر النص الموازي، حتى كاد يستقل بعلم خاص هو علم العنونة أو

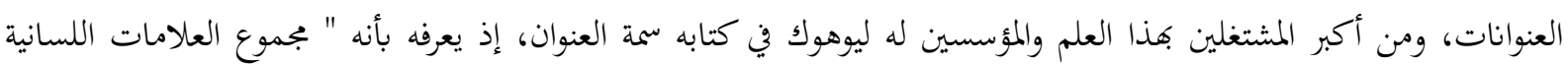
كلمات مفردة، أو جمل أو نص يمكن أن تدرج على رأس نصه لتحدده وتدل على محتواه العام وتعرف الجمهور بقراءته" (رضا، 
عامر، 2014، ص125). وقد حدد جرار جينيت أربع وظائف للعنوان هي: الوظيفة التعينية، أو التحديدية، والوظيفة الوصفية،

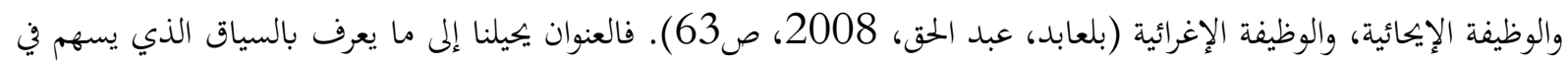

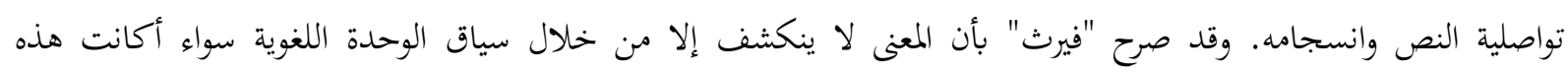

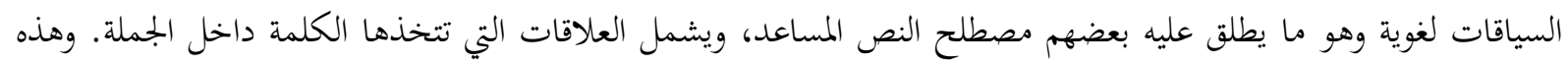

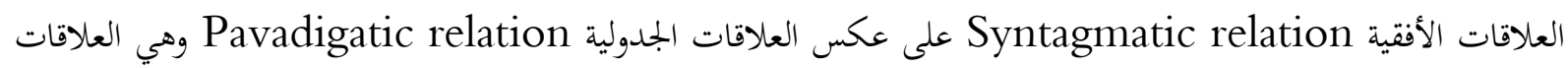

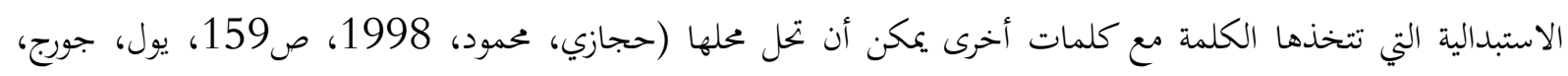

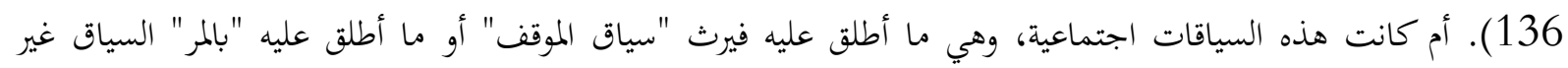

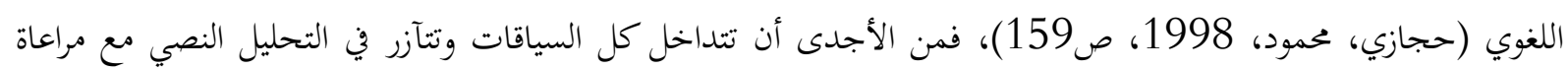

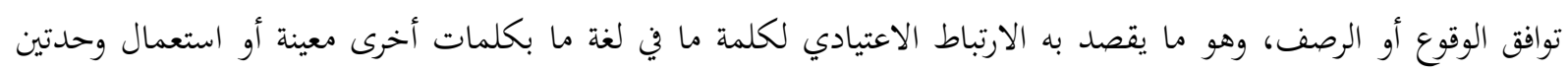

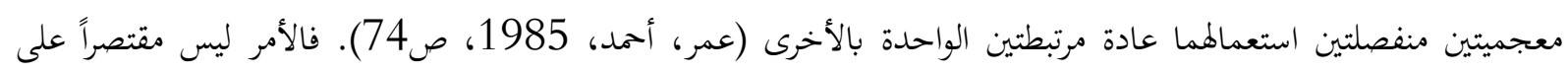

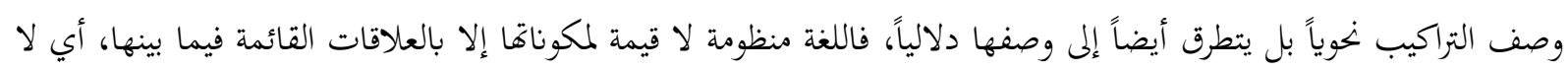

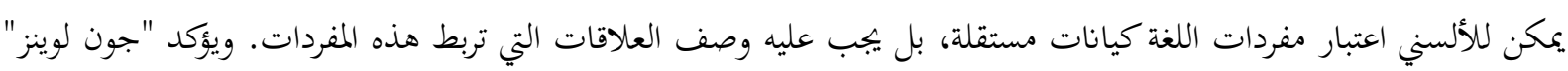

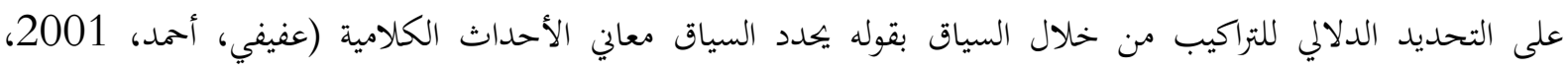

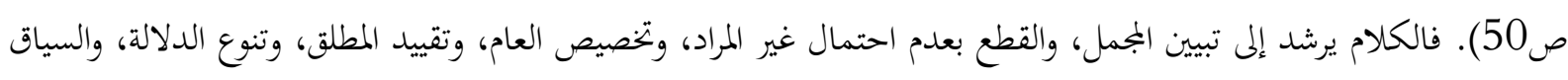

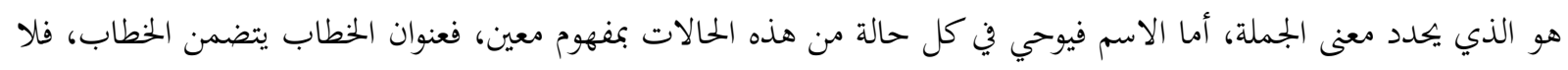

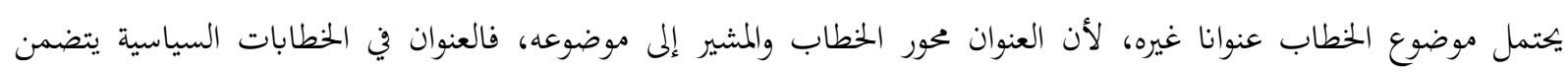
الموضوع الأساسي في الخطاب. مع تتبع خطابات السلطان الراحل حضرة صاحب الجلالة السلطان قابوس بن سعيد طيب الله ثراه يتضح أن هذه

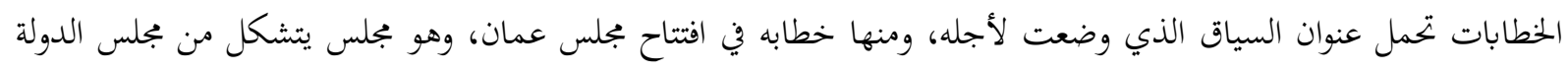

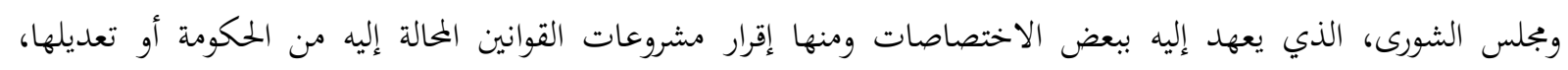

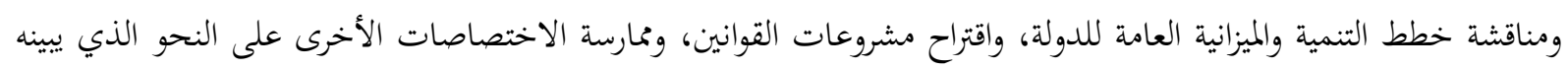
القانون.

وقد صدر قانون بجلس عمان بموجب المرسوم السلطاني رقم (2021/7) مبيناً الفئات التي يتم من بينها الاختيار لعضوية

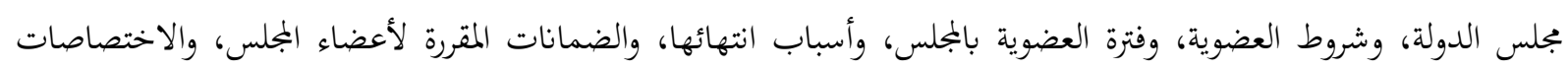

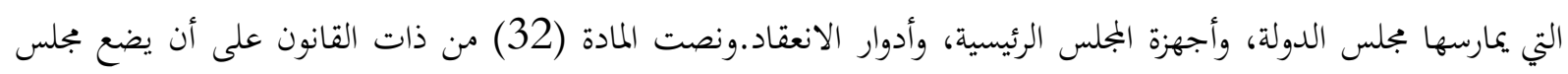

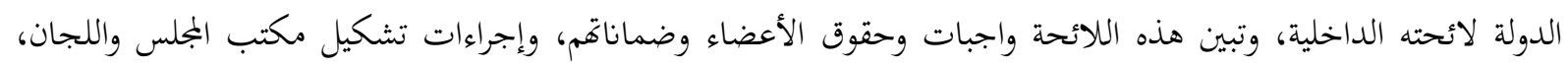

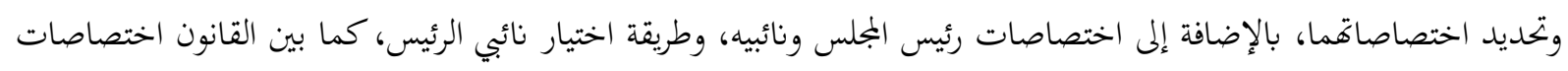
الأمانة العامة بالمجلس.

بنية الخطاب:

يتكون الخطاب من بنى مترابطة، ومنسجمة في مقاصدها، فتنضبط بالمقصدية التي ينشدها منتج النص، فعند استماعنا

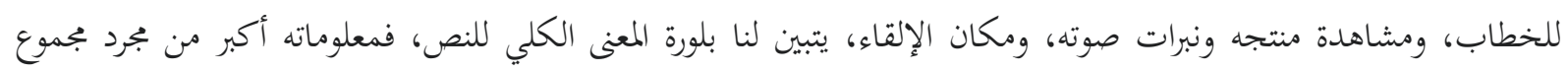

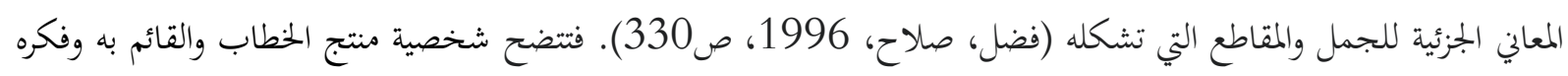
في خطابه، فمنتج الخطاب السلطان الراحل حضرة صاحب الجلابة السلطان قابوس بن سعيد طيب الله ثراه، وهو 
السلطان التاسع لسلطنة عُمان ورئيس مجلس الوزراء، ووزير الدفاع، والخارجية، والمالية، وحاكم البنك المركزي، والقائد الأعلى للقوات المسلحة، والحاكم الثاني عشر لأسرة آل بو سعيد، عُدَّ صاحب أطول فترة حكم من بين الحكام العرب والثالث في العالم

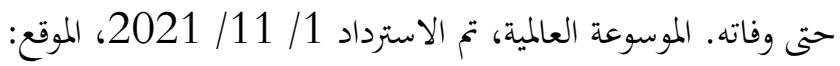
(https://ar.wikipedia.org/wiki/\%D9\%82\%D8\%A7\%D8\%A8\%D9\%88\%D8\%B3_\% D8\%A8\%D 9\%86_\%D8\%B3\%D8\%B9\%D9\%8A\%D8\%AF)

عرف بحنكته السياسية داخليا وخارجيا، فقد استطاع أن يؤمن سياسته الخارجية ويقيم علاقات ودية مع كل أقطار العالم،

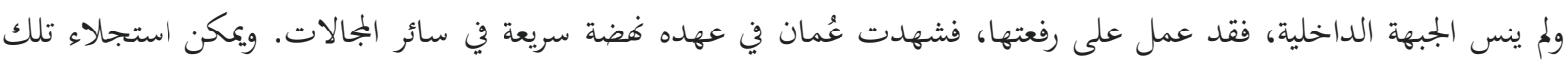

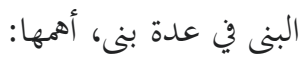

1- البنية الأولى: وتتمثل هذه البنية في مستهل الخطاب تحديدا، وهي جملة تتضمن معنى الحمد، وهذا دأب صاحب الجلالة السلطان قابوس طيب الله ثراه، في كل خطاباته، فقد كان يبدأ خطابه بالبسملة، ثم الحمدلة، رابطا الحمد بمضمون خطابه، وهذا فهذه طيب الله ثراه، ففي افتتاح الدورة الثانية لمجلس عمان ربط الحمدلة بالشورى بقوله الحمد لله الذي جعل الشورى منهجا من

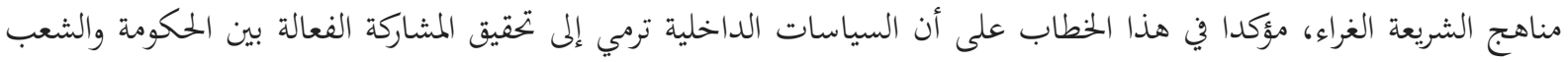

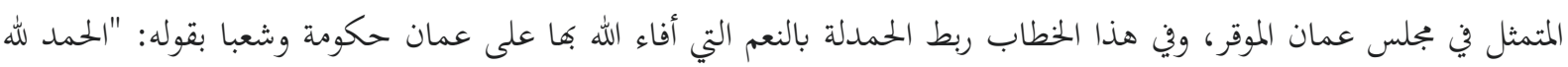

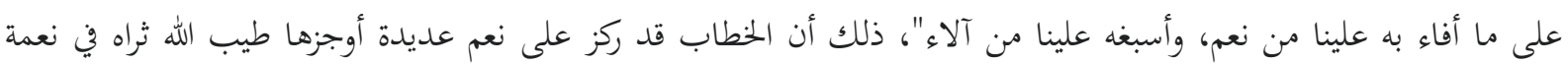

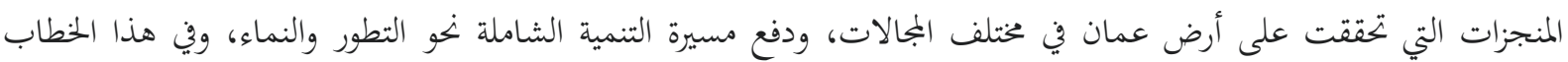

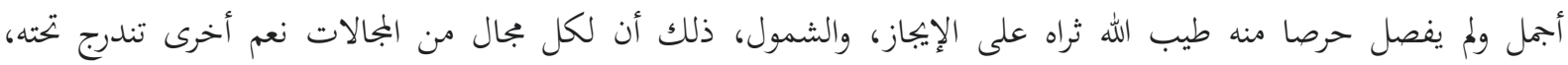
وتتضمنه، ولعل أهم نعمة تمتعت بها عمان نعمة الأمن والأمان.

2- البنية الثانية: متن الخطاب، ولا يمكننا أن نعدها بنية مستقلة في اللسانيات النصية، لأن النص بنية واحدة تتضافر معه مجموعة من البنى لتشكل بنيته الكلية، وقد تضمن المتن مجموعة من البنى التي تخدم مقصد منتج الخطاب، ولعل أهم هذه البنى، هو

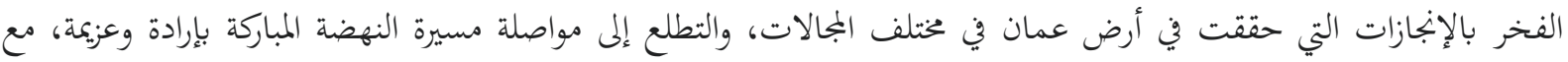
ضرورة تكاتف الجهود وتكاملها. 3- البنية الثالثة: الخاتمة، وفيها الدعاء الذي فجه صاحب الجلالة السلطان قابوس بن سعيد طيب الله ثراه، في كل خطاباته، مؤكدا على ربط الدعاء (الخاتمة) بموضوع الخطاب، وبما أن موضوع الخطاب هنا هو السعي إلى مواصلة مسيرة النهضة المباركة،

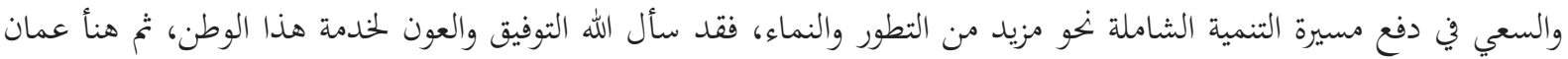
(بلادنا العزيزة) وأبناؤها الأوفياء في خير ومسرة، وهذه التهئة حملها صاحب الجلالة السلطان قابوس بن سعيد طيب الله ثراه

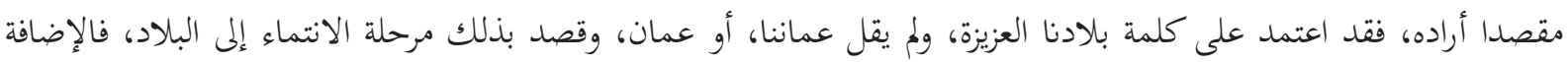

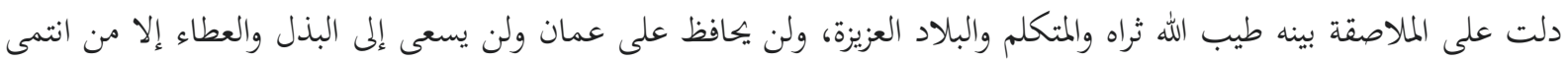

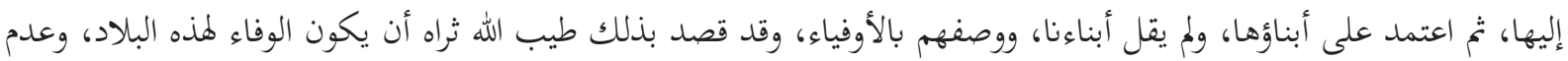

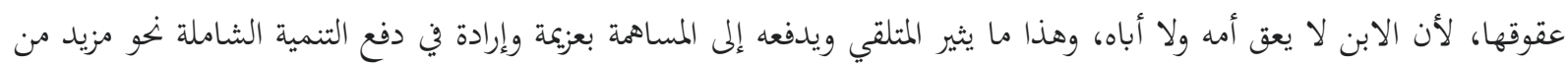
التطور والنماء.

4- السياق ودوره في الحطاب: وندرك من الخطاب السامي لخضرة صاحب الجلالة السلطان الراحل السلطان قابوس بن سعيد طيب الله ثراه، أنه راعى منزلة متلقي الخطاب ومستقبله، فالمتلقي فردا كان أم جماعة، أم شعبا، فهو يسعى لإقناع المتلقين، فقد 
استخدم الوسائل الثقافية والدينية، واللغوية، فقد وظف منتج الخطاب الثقافة الدينية، فقد سبق الخطاب تلاوة آيات من الذكر الحكيم تلاها القارئ طالب بن سعيد القنوبي، وهي آيات اختارها منتج الخطاب.

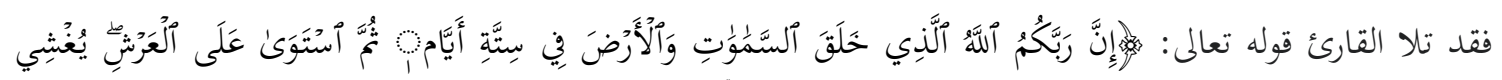

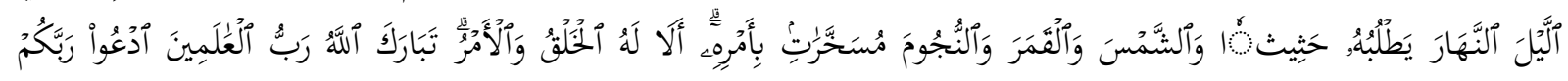

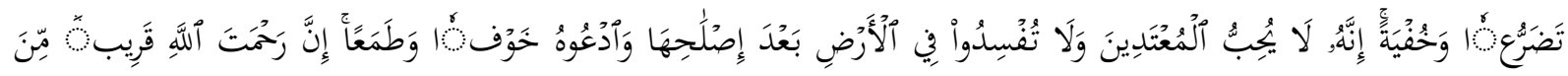

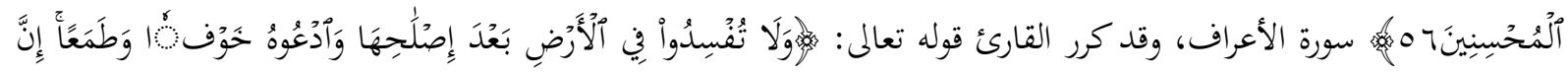

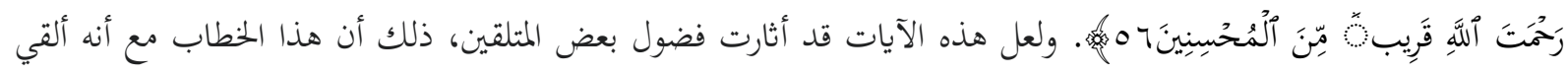

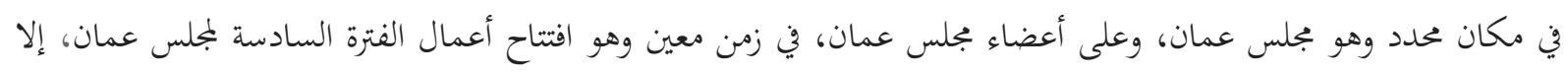

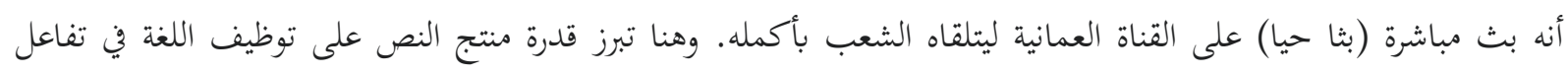

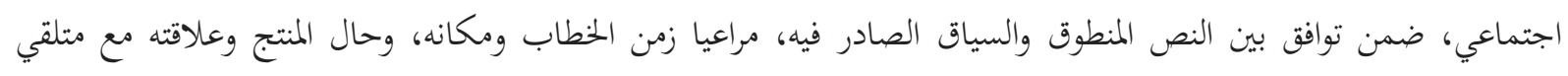

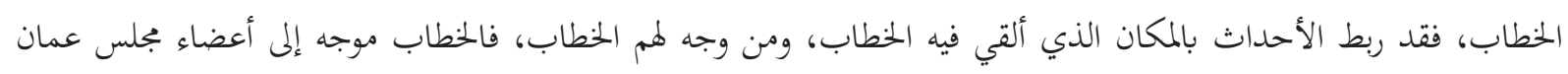

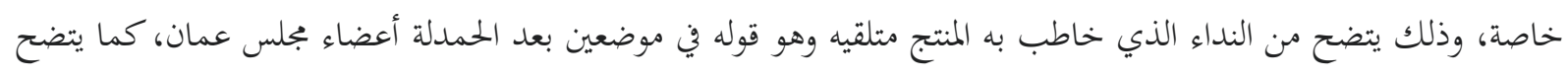

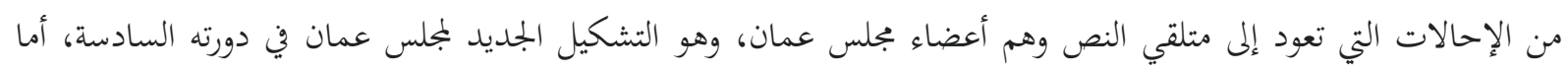

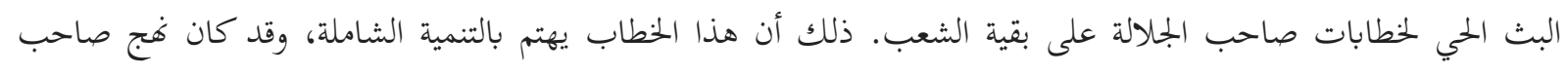
الجلالة السلطان قابوس بن سعيد المعظم طيب الله ثراه إنما يلقي خطاباته مباشرة على شعبه ويبين لهم الخطط التنموية الشاملة،

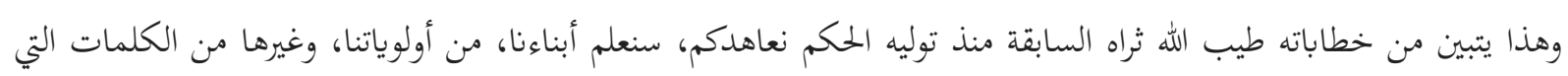
تبين اهتمامه طيب الله ثراه بالتنمية الشاملة، وحرصه على أن يدرك الشعب الخطوات التي ستبنى عليها التنمية الشاملة.

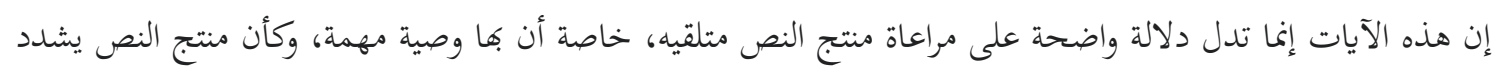

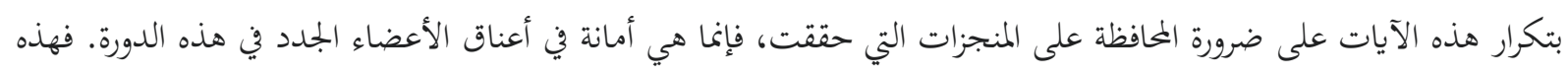

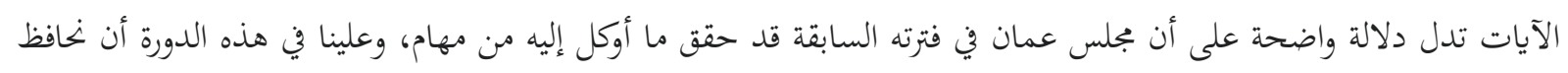

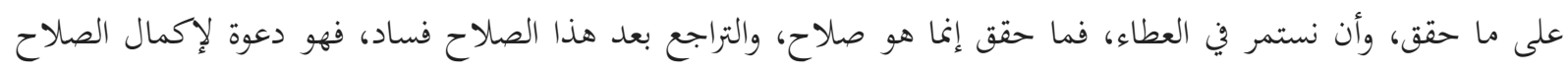

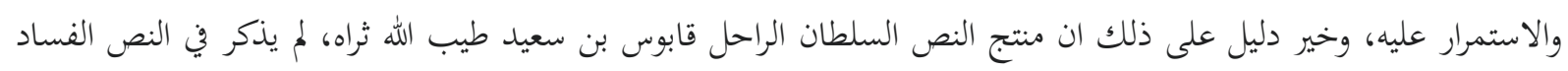

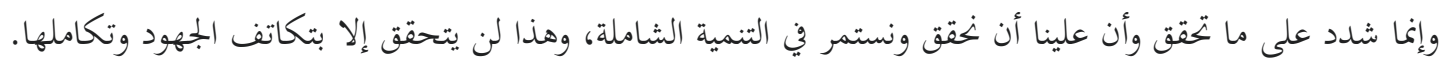
لعل متلقي الخطاب لم يتبين الإنجازات التي حققت على أرض عمان، مع أن صاحب الجلالة طيب الله ثراه قد أجمل هذه

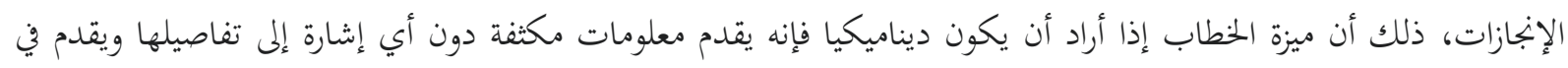

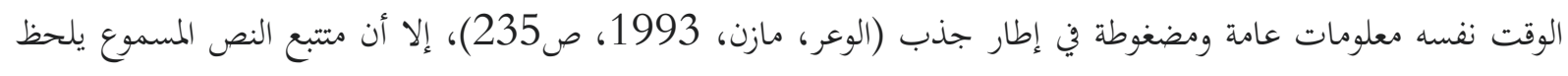
أن السياق المصاحب للنص، قبل بداية الخطاب قد عدد الإنجازات التي حققتها السلطنة في كافة المجالات.

\section{المستويات التحليلية في الخطاب:}

ارتكز خطاب صاحب الجلالة طيب الله ثراه في افتتاح الفترة السادسة لمجلس عمان، على المستويات اللغوية المختلفة، وهي

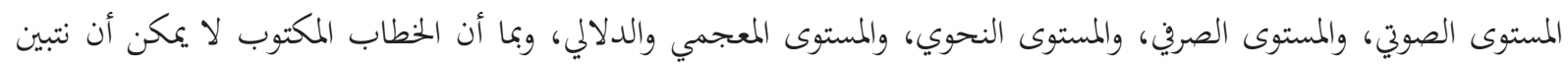

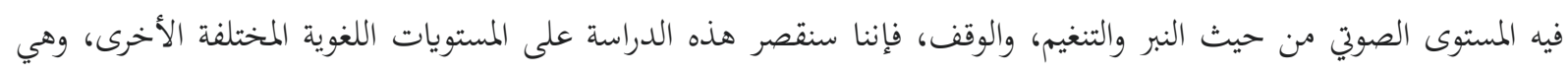

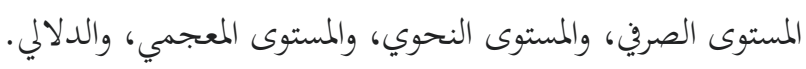


وردت الأفعال في خطاب صاحب الجلالة السلطان قابوس طيب الله ثراه ستة عشر مرة، وقد اعتمد في تسع مرات على

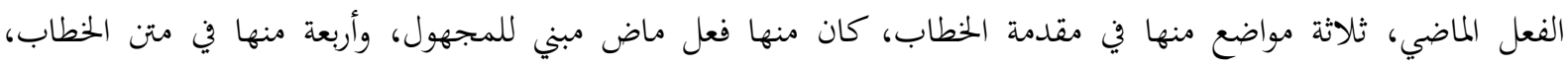

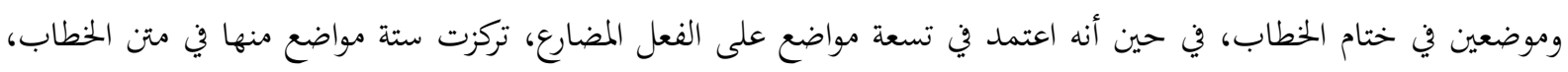

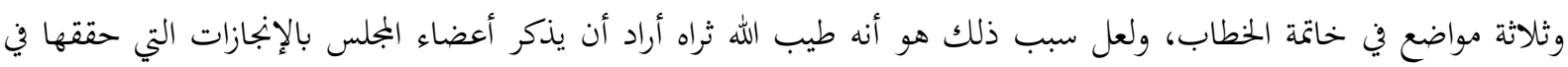
الماضي، ليحث الأعضاء الجلدد على العمل بعزيمة لمواصلة مسيرة النهضة المباركة، والفعل الماضي يدل دلالة واضحة على على الإنجازات التي تمت، فخطبه طيب الله ثراه تخظى باهتمام الجهات السياسية والمؤسسات الإعلامية، فقد كان يطلع شعبه على بعلى بحريات مسيرة التنمية والنهضة التي قادها، وسياسات حكومته داخليا وخارجيا، لذلك يذكر الإنجازات التي تمت في الفترة السابقة، وهي إنجازات قد وضعت في خطط مجلس عمان، ونوقشت، وحققت ثناء من لدن صاحب الجلالة السلطان قابوس طيب الله ثراه.

المستوى النحوي:

إن الجمل النواة الأساسية تصاغ على حد تعبير تشومسكي في جملة تحويلية مشتقة واحدة، عن طريق استخدام أدوات

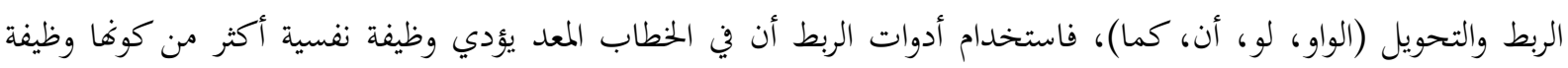

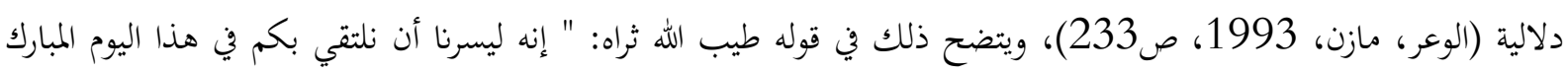

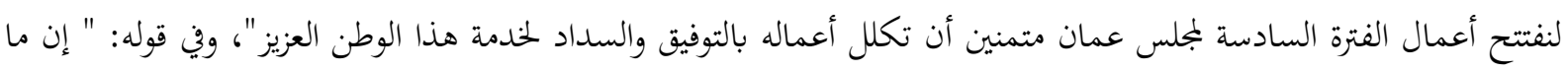

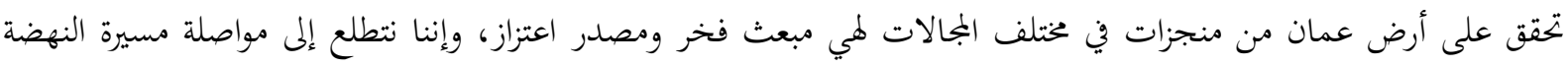

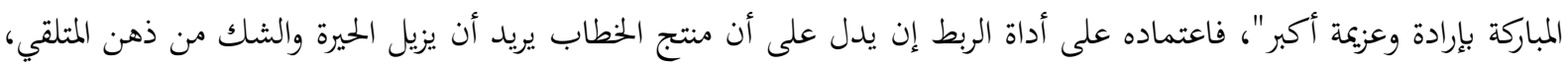

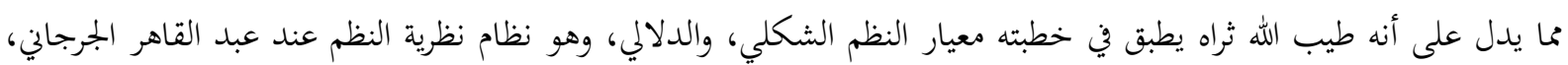
وقد اعتمد في ذلك على مجموعة من الإستراتيجيات اللغوية، أهمها:

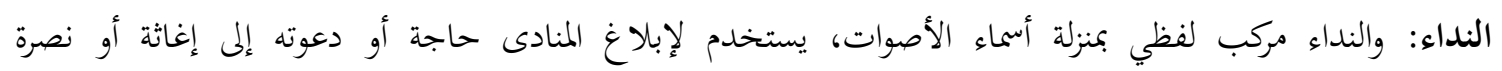

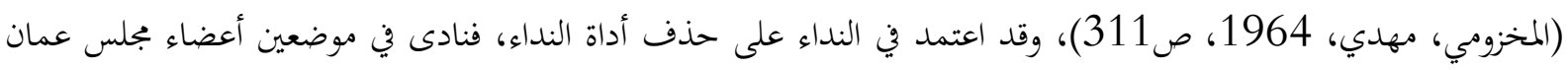

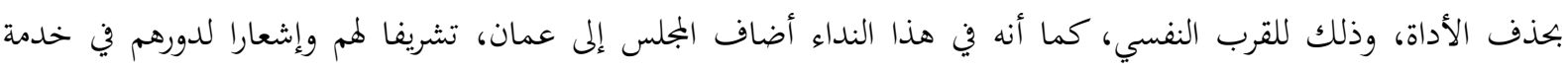

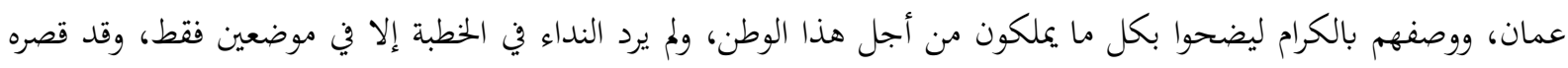

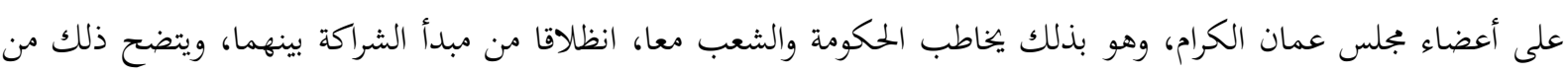

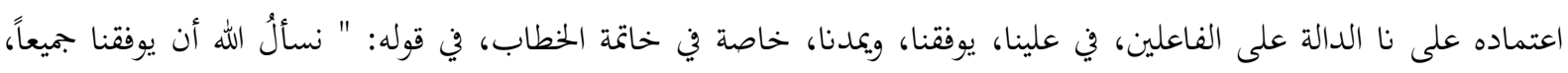

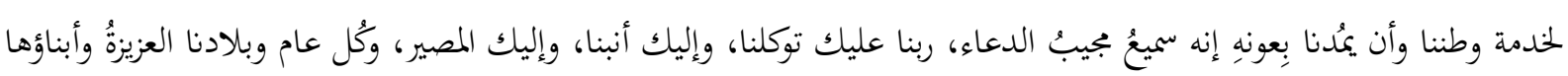
الأوفياء في خير ومسرة".

فقد شارك منتج النص المتلقي في طلب التوفيق من الله، وذلك ليقينه بأن مسيرة التنمية إنما هي شراكة بين الحكومة

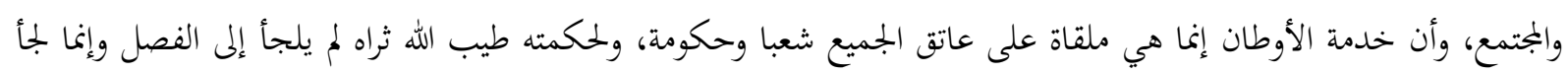

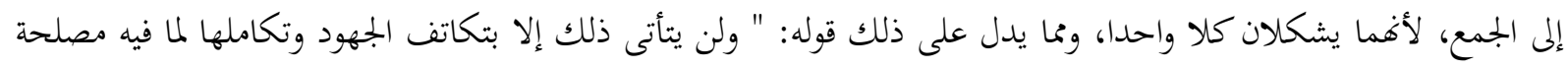

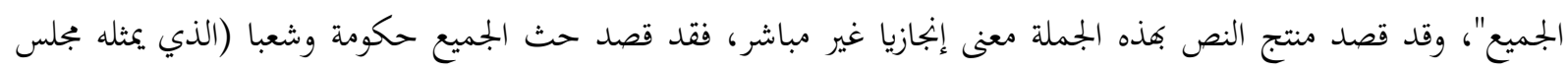

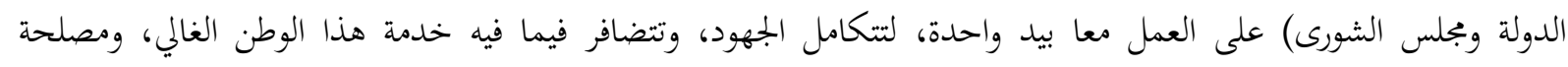

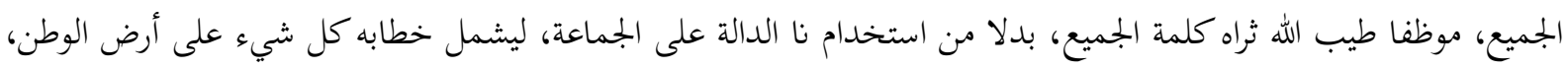
يمكنه الاستفادة من هذه النهضة المباركة. 
ويمكن أن يتضمن هذا الفعل الإنجازي غير المباشر النهي، وهو في عن التشتت والتفرقة، وقد اعتمد في ذلك على أداة

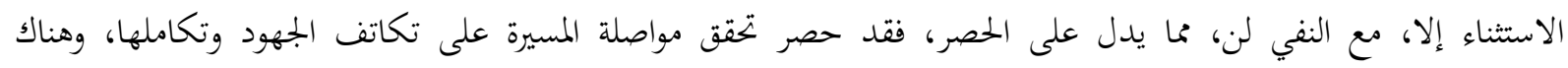

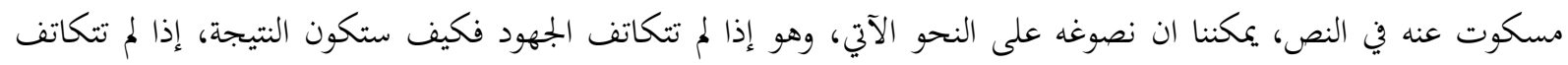
فإن النتيجة ستكون فتفشلوا وتذهب ريكهم.

ولن تتحقق المسيرة كما هو مرسوم لها، لذلك حث على التكاتف مراعيا مصلحة الجميع، ولذلك فقد اعتمد على

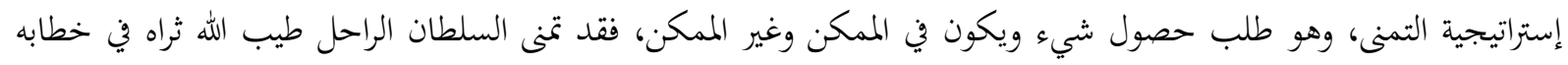

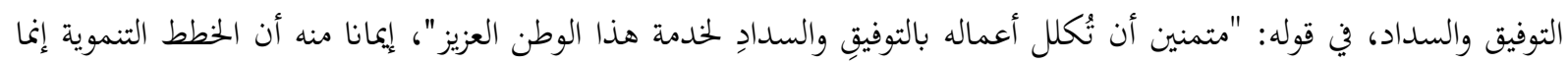
هي خطط مدروسة تحقيق إلى عزيمة المجلس، وتوفيق الحق تبارك وتعالى لتحقيقها، ومما يدل على ذلك: قوله طيب الله ثراه: "وإننا نتطلعُ إلى مواصلة مسيرة النهضة المباركة، بإرادة وعزيمة أكبر".

لعل أهم عنصر نقف عنده في هذا المستوى عنصر الاستبدال، ذلك أن الاستبدال عنصر من عناصر ترابط النص واتساقه،

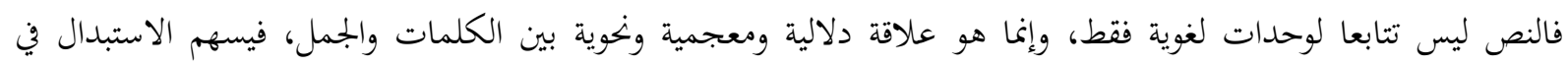

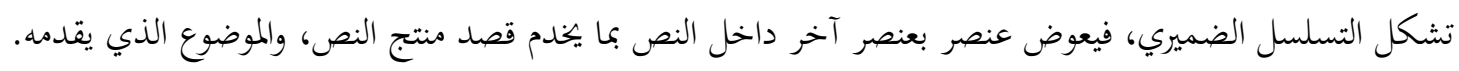
ونلمس ذلك في خطب صاحب الجلالة السلطان قابوس بن سعيد طيب الله ثراه، فكان ينتقي الكلمات التي تخدم موضوعه، وقصده في خطابه، ويتبين ذلك في مواضع عدة في مقدمة خطابه في متن خطابه ويف خاتمة خطابه، من ذلك:

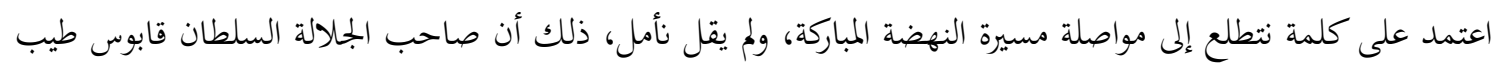

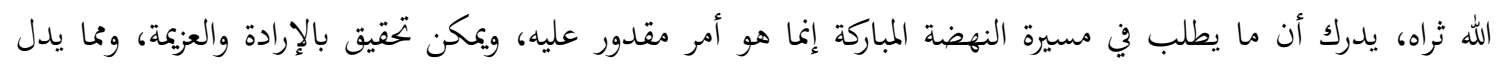

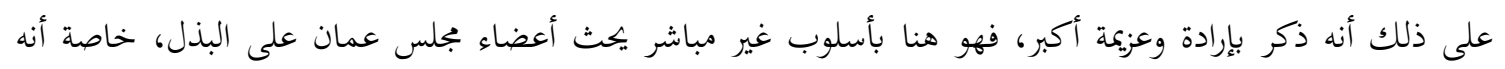

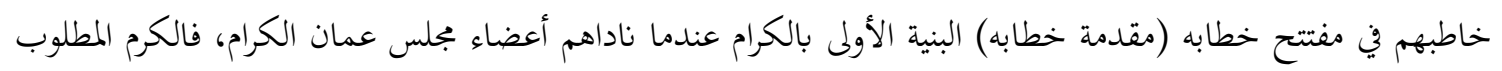
في مجلس عمان هو البذل في سبيل تحقيق الإنجازات المختلفة، وقد أدرك طيب الله ثراه أنه لو اعتمد على على كلمة نأنساء تأمل وكأنه

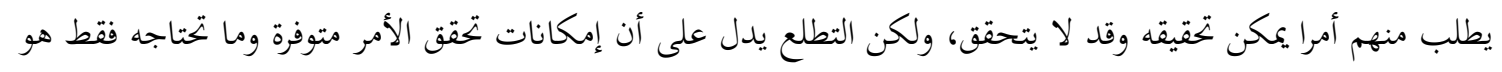
البذل والتضحية. اعتمد على كلمة "تابعنا" في قوله ولقد تابعنا عن كثب أعمال مجلس عمان بشقيه مجلس الشورى وبجلس الدولة، ولم

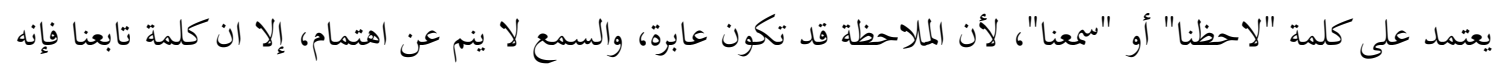
يدل على حرص واهتمام، وهو يدل بصورة غير مباشرة على اهتمام صاحب الجلالة السلطان قابوس طيب الله ثراه، وحرصه على ما يقدم في هذا المجلس الذي يحمل اسم عمان، واهتمامه بالنهضة بلمه المباركة وأنه يتابعها بنفسه.

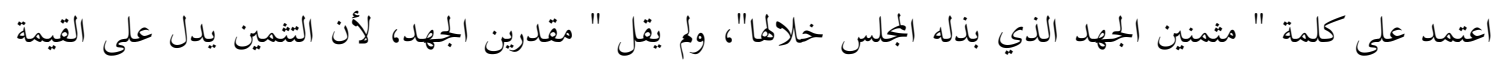

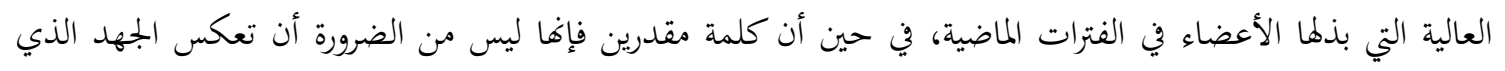

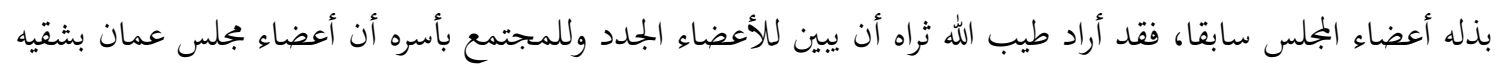

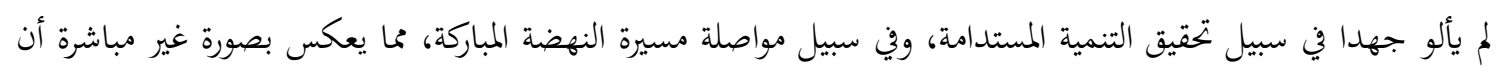

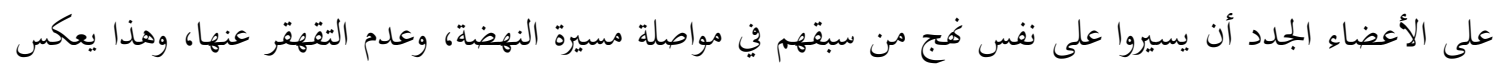

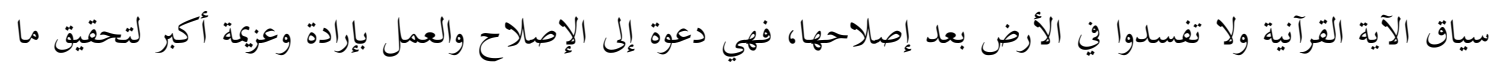
يرجوه طيب الله ثراه، وما يرجوه المجتمع من هذا المجلس. 
بينت هذه الدراسة أن الخطاب السياسي للمقام السامي لحضرة صاحب الجلالة السلطان قابوس بن سعيد طيب الله ثراه

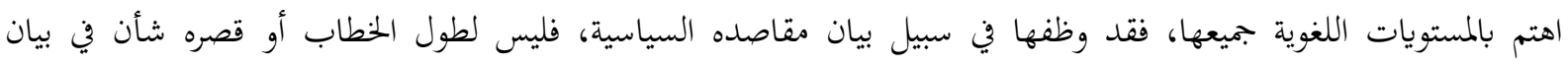

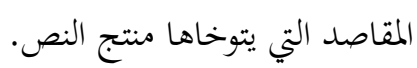

كما بينت هذه الدراسة أن خطاب السلطان الراحل طيب الله ثراه تكون من بنى مترابطة، ومنسجمة في مقاصدها، فراعى في تشكيله المتلقي، والمقام، فكان للسياق اللغوي وغير اللغوي دور في بيان قصد المخاطِب.من إستراتيجيات الخطاب التنموي

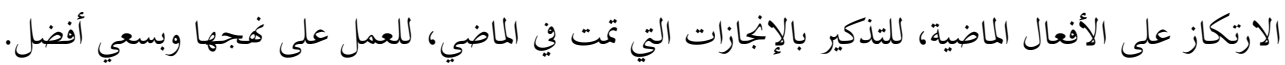




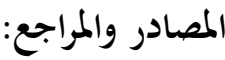

إبراهيه، عبدالله (1993م)، إنكالية المصطلح النقدي (الخطاب والنص) مجلة آفاق العربية.

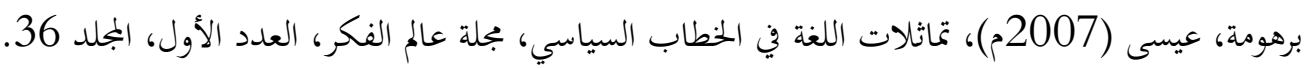

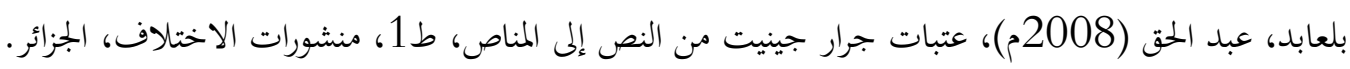

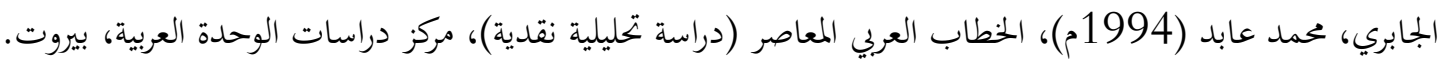
حجازي، محمود فهمي (1998م)، مدخل إلى علم اللغة، دار قباء للطباعة، القاهرة.

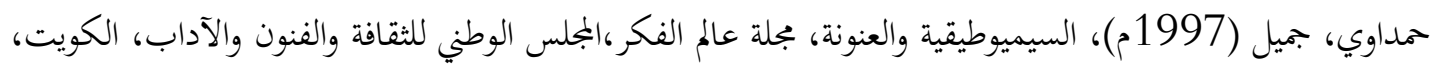
م25، عدد 3.

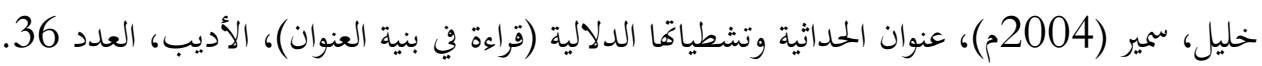

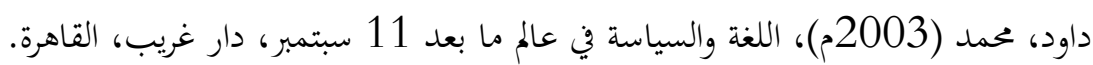

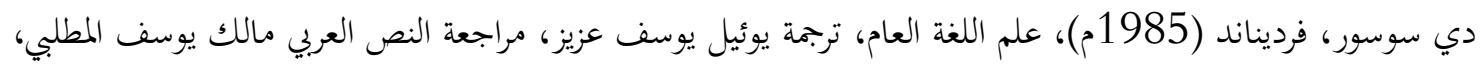
دار آفاق عربية، العراق.

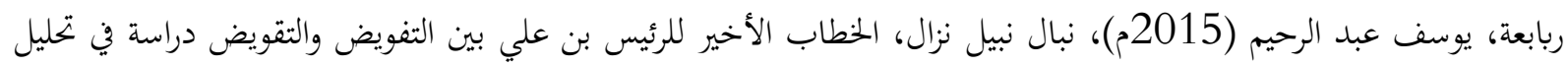

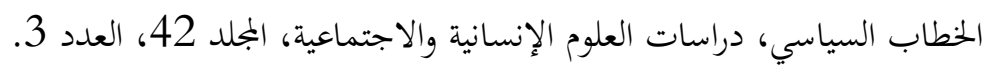

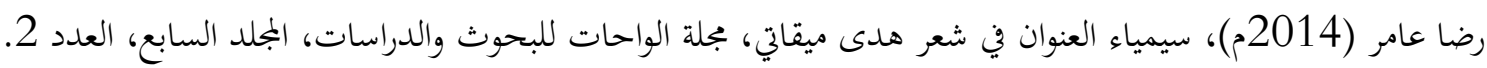
الزين، محمد (2017م)، الحجاج في الخطاب السياسي.

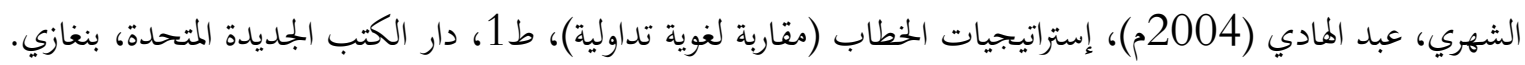

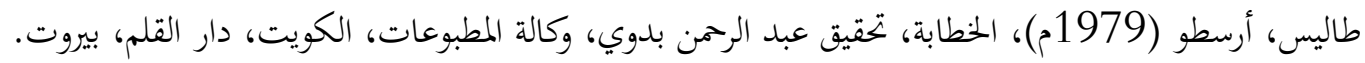

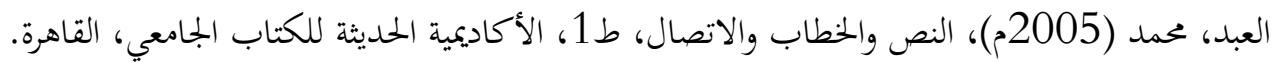

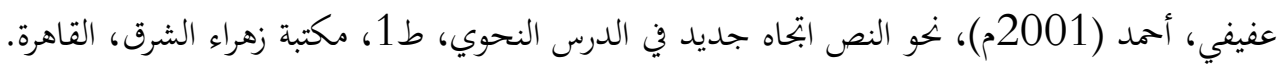

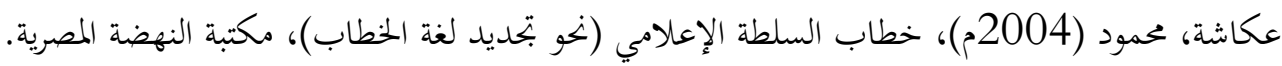

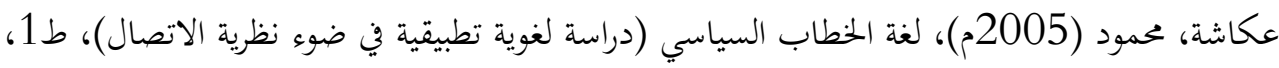
دار النشر للجامعات، مصر.

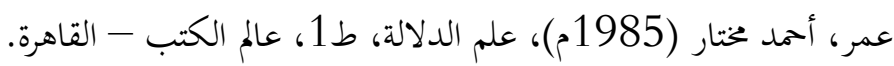

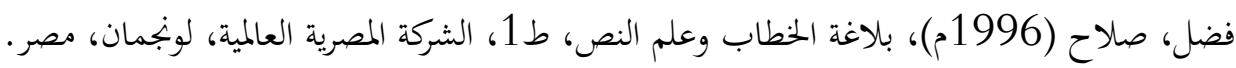
فوكو، ميشيل، نظام الخطاب، ترجمة حممد سبيلا، مطبعة التنوير.

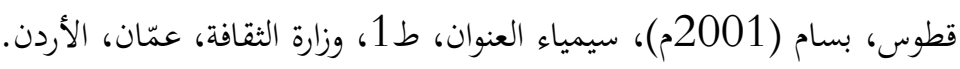

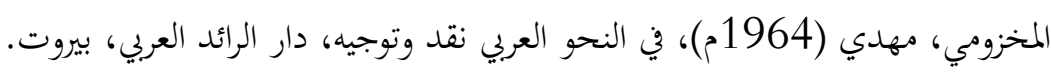

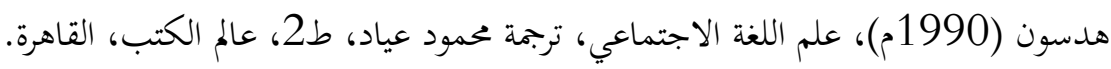

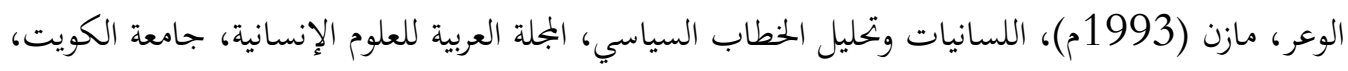

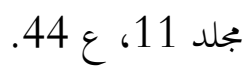
يول، جورج، معرفة اللغة، ترجمة عمود فراج عبد الحافظ، دار الوفاء لدنيا الطباعة والنشر، الإسكندرية. https://www.mol.om/His-Majesty-Speech

https://www.youtube.com/watch?v=rBBPc9uSU5g 